UCRL-ID-118528

\title{
NIF Target Fill, Transport and Insertion Cryostat
}

\author{
R. Warren
}

September 20, 1994

This is an informal report intended primarily for internal or limited external distribution. The opinions and conclusions stated are those of the author and may or may not be those of the Laboratory.

Work performed under the auspices of the U.S. Department of Energy by the Lawrence Livermore National Laboratory under Contract W-7405-Eng-48.

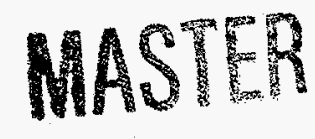




\section{DISCLAIMER}

This document was prepared as an account of work sponsored by an agency of the United States Government. Neither the United States Government nor the University of California nor any of their employees, makes any warranty, express or implied, or assumes any legal liability or responsibility for the accuracy, completeness, or usefulness of any information, spparatus, product, or process disclosed, or represents that its use would not infringe privately owned rights. Reference herein to any specific commercial products, proces, or service by trade name, trademark, manufacturer, or otherwise, does not necessarily constitute or imply its endorsement, recommendation, or favoring by the United States Government or the University of California. The views and opinions of authors expressed herein do not necessarily state or reflect those of the United States Government or the University of California, and shall not be used for advertising or product endorsement purposes.

This report has been reproduced directly from the best available copy.

Available to DOE and DOE contractors from the Office of Scientific and Technical Information

P.O. Box 62, Oak Ridge, TN 37831

Prices available from (615) 576-8401, FTS 626-8401

A vailable to the public from the

National Technical Information Service

U.S. Department of Commerce

5285 Port Royal Rd.,

Springfield, VA 22161 


\section{DISCLAIMER}

Portions of this document may be illegible in electronic image products. Images are produced from the best available original document. 


\title{
TARGET FILL, TRANSPORT AND INSERTION CRYOSTAT
}

\begin{abstract}
A cryostat to support the fielding of a cryogenic target within the NIF is described. The present design is predicated upon fuel layer symmetry being achieved with the $\beta$ layering process and modifications needed for other fuel symmetrization processes are discussed.
\end{abstract}

\section{DESCRIPTION}

This cryostat which supplies target refrigeration subsequent to a high pressure diffusion fill and which accompanies the target sequentially through the fill, layering and characterization procedures and into the NIF target chamber, is shown on Figure 1. Prior to loading cryogens, the unfilled target is assembled to the cryostat extension. The high pressure diffusion fill chamber is mated to the target mount and the vacuum chamber extension is placed over the cryostat extension and mated to the cryostat vacuum enclosure. During the fill procedure, the vacuum jacket extension, which is independently evacuated from the larger cryostat volume, also provides a secondary containment function. The diffusion fill is accomplished by pressurizing both within and outside of the hohlraum. The pressure difference between these two regions must be less than the burst strength of the hohlraum windows which is about $10^{5} \mathrm{~Pa}^{1}$. If the hohlraum windows can be made somewhat impermeable to gaseous diffusion, possibly with a thin metallic coating, the external pressurant could be a gas other than DT fuel

\footnotetext{
1 Window support might be incorporated into clamshell "fillers" which are otherwise used to reduce the quantity of external pressurant and which are assembled around the target and target extension prior to the mating of the diffusion fill chamber to the target mount. In this case, the pressure difference can exceed the unsupported window strength, but for outwardly domed windows the internal pressure must of course exceed that on the outside.
} 
which would greatly reduce the DT inventory. A metallic coating may also be needed to increase the infrared reflectivity of the windows but it is not known whether this amount of metallizing would be sufficient to reduce the gaseous diffusion rate across the window to acceptable levels. Aluminum at a thickness of $100 \AA$ however, has been observed to provide an effective permeation barrier against deuterium for paralene coated ICF capsules ${ }^{2}$.

Following diffusion filling of the target, cryogens are loaded within the cryostat. The initial target cool down is accomplished by circulation of liquid helium through the target mount heat exchanger. This flow is initiated by a reduction in the vent line pressure downstream of the heat exchangers. The liquid helium is vaporized and the vapor is super heated in the target mount heat exchanger prior to further super heating in the cryostat extension heat exchanger. The temperature and pressure in the diffusion fill chamber are reduced to allow removal of the DT mixture without a subsequent over pressurization of the capsule. A temperature on the order of $60 \mathrm{~K}$ will insure a safe capsule pressure. Following the attainment of a low vacuum within the pressurization chamber, helium is introduced so as to maintain continuum heat transfer and the balance of the DT is purged and replaced with helium at a pressure level just sufficient to provide an efficient purging process; likely 10 Torr or less. When a negligible level of DT is achieved within the pressurization chamber, the helium pressure is lowered further but kept within the continuum regime. The helium flow to the target mount heat exchanger is increased with an attendant lowering of the temperature of the diffusion fill chamber and cryopumping of any residual DT which presumably will be a very small quantity. The target is now heat sunk, with small temperature difference, to the diffusion fill chamber via the helium exchange gas and the fuel within the capsule will freeze as the temperature falls through the triple point.

2 Kim????? 
Next, flow of the high pressure helium coolant is commenced. This flow passes sequentially through the heat exchangers located in the nitrogen bath, on the vapor cooled shield enclosing the helium reservoir, and finally on the helium reservoir before reaching the hohlraum heat exchangers. At this stage, because of the presence of the helium exchange gas within the pressurization chamber, this flow will not materially affect the cooling of the hohlraum.

If not already located within the target characterization vacuum chamber, the cryostat is moved to within this chamber and the chamber is evacuated. The conical vacuum shell extension is removed, followed by removal of the diffusion fill chamber and installation of the blast shield which protects the target mount. With removal of the diffusion fill chamber, the target is now exposed to a relatively good vacuum and the removal of the decay and irradiation heats are now entirely by heat transfer to the high pressure helium coolant within the hohlraum heat exchangers. The symmetrization of this cooling with respect to the capsule is such as to allow the $\beta$ layering process to produce a uniform DT layer. The helium flow to the target mount heat exchanger is reduced and the target mount temperature rises to the neighborhood of $60 \mathrm{~K}$. Once optical characterization has been completed, the conical vacuum extension is replaced and the target cryostat taken from the characterization chamber and is moved to the NIF and placed within the target insertion chamber. The conical vacuum chamber extension is removed and the cryostat is inserted into the target chamber. The target is now exposed to the target chamber vacuum. 


\section{DEVELOPMENT WORK NEEDED}

\section{CAPSULE COOLING}

The uniformity of the fuel layer thickness obtained with the $\beta$ layering process is dependent upon the symmetry of the capsule cooling. This symmetry is achieved by elimination of convection within the hohlraum and by specifying the temperature profile in the hohlraum wall. The thermal design will be determined from a finite element analysis which will consider alloying of the gold hohlraum wall and varying it's thickness to achieve an appropriate thermal conductance ${ }^{3}$, and the placement of heaters and heat exchangers on the hohlraum wall.

\section{DIFFUSION FILL}

\section{Minimization of DT Inventory}

Two methods to minimize the DT inventory are proposed; use of clamshell fillers within the high pressure chamber and/or use of a gas other than DT outside of the hohlraum. In order to address the feasibility of these, a detailed design of the target support structure must be completed to allow an assessment of the difficulty in fitting up the clamshells and further experimentation is needed to assess the effect of metallic coatings on the gaseous diffusion across the hohlraum windows. Because of activation considerations, the fitting up of the clamshells to the target may have to take place within a glove box.

\footnotetext{
${ }^{3}$ A few atomic percent addition of iron will drastically effect the thermal conductivity of otherwise pure gold.
} 


\section{Diffusion Fill Procedures}

The diffusion fill procedures outlined above must be refined to reflect the realities relative to the handling of DT.

\section{Convection Suppression of Hohlraum Fill Gas}

The need for a large fraction of an atmosphere of gas pressure in the hohlraum at shot time for the purpose of tamping the hohlraum wall maybe inconsistent with the need to suppress convection within the hohlraum. Two ways around this are suggested; to keep the pressure low until just prior to shot time and then raise the pressure rapidly and to further subdivide the interior of the hohlraum with thin membranes. In the first approach, the gas is introduced at a temperature approximating that of the capsule and thus does not introduce a large thermal perturbation, however, the fluid dynamics may tend to introduce a mechanical perturbation which possibly can be minimized by utilizing oppositely apposed nozzles with adequate attention to diffuser design. The

ultimate extension of the second approach would result in the filling of the hohlraum with a foam. This foam would need to be of such low density, however, that it is not at all clear that such a material could be produced.

\section{OTHER CAPSULE/FUEL ORIENTATION DESIGNS}

The present cryostat design has been predicated upon a target with solid DT layers symmetrized by $\beta$ decay. Other fuel orientation techniques are presently considered. These include the vertically differentially heated capsule with a uniform liquid layer stabilized by a surface tension gradient, foam supported liquid layers and solid $\mathrm{D}_{2}$ or $\mathrm{HD}$ layers symmetrized by bulk irradiation from a laser source. The cold sinks to be incorporated in these techniques could, in principal, be 
cooled with the high pressure helium envisioned for the heat sink rings of the present design. Supplementary laser access would be provided for differential heating of the capsul for surface tension gradient stabilization of a liquid layer or bulk heating of a solid layer. The cryostat in each of these cases would look substantially the same as in the present case with the only significant differences being in the details of the design in the immediate vicinity of the target. 


\section{Target Life Support and Cryo Conditioning System page 1 of 3}

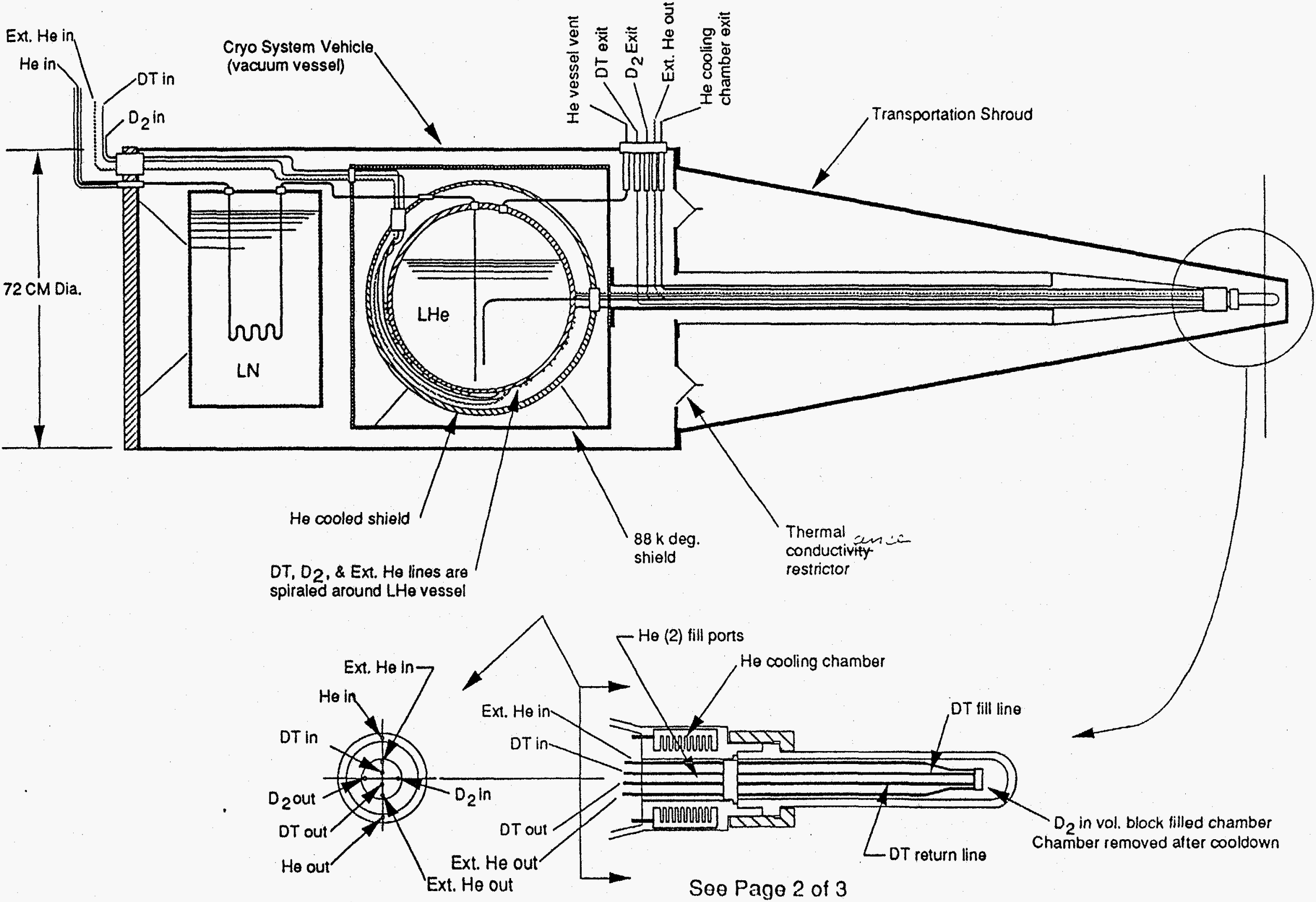




\section{Target Life Support and Cryo Conditioning System page 2 of 3}

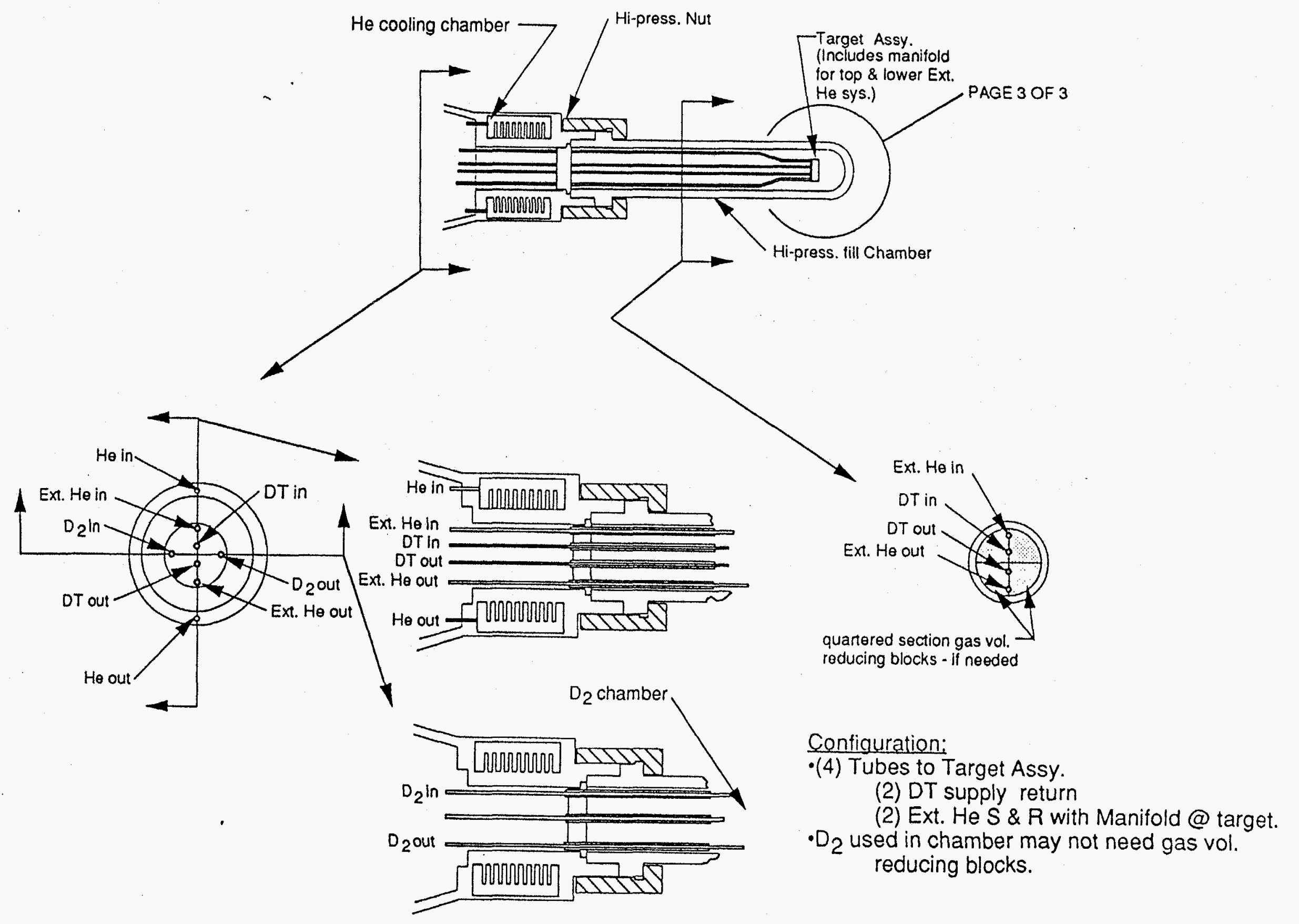




\section{Target Life Support and Cryo Conditioning System Page 3 of 3}

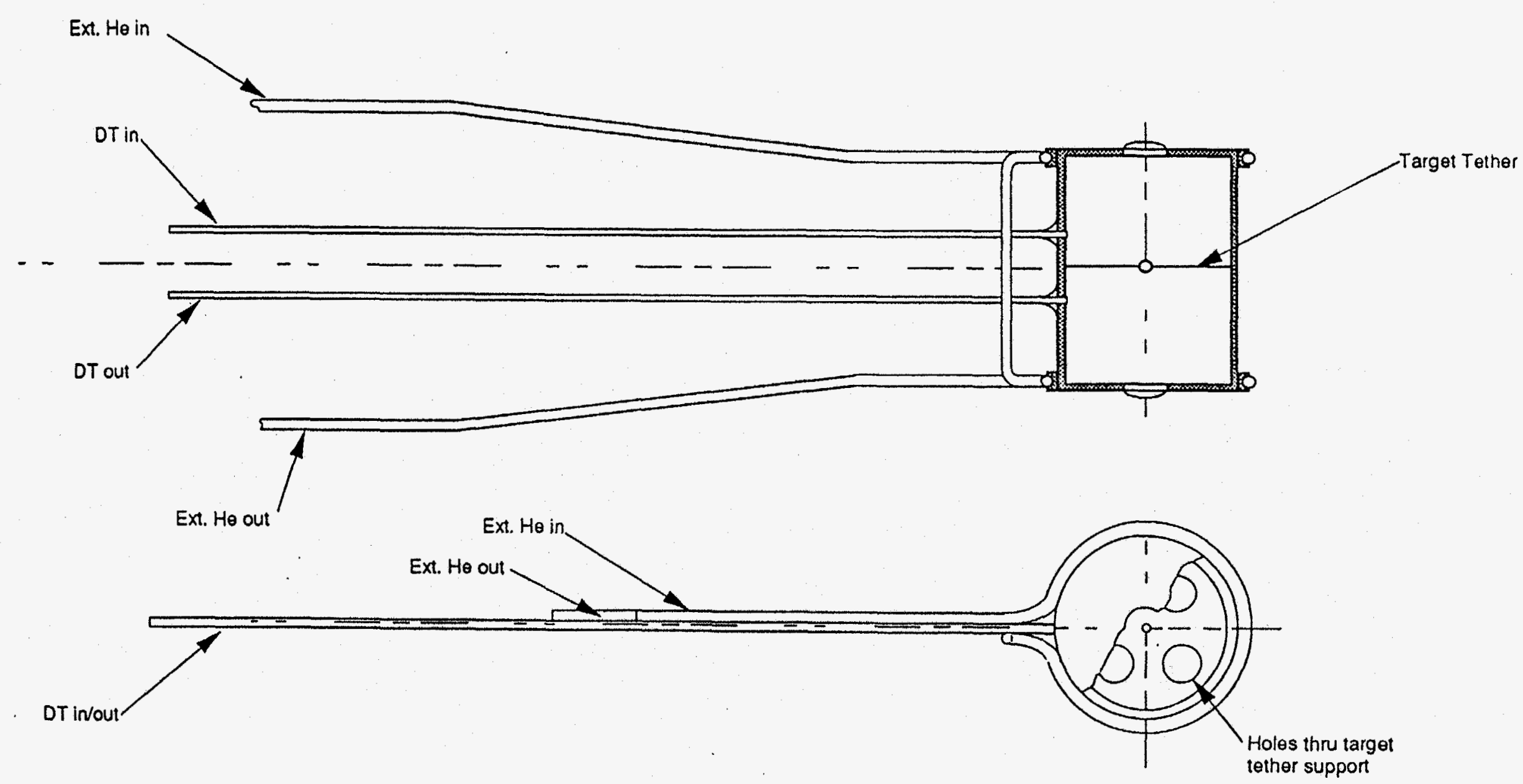

